\title{
KERATOCONUS EXPERIMENTALLY PRODUCED IN THE RAT BY VITAMIN A DEFICIENCY
}

\author{
BY \\ J. R. MUTCH, M.D., D.O.M.S. \\ AN D \\ M. B. RichaRDS, M.A., D.SC. \\ ROWETT RESEARCH INSTITUTE, ABËRDEN
}

Keratoconus is comparatively speaking a rare disease, but as a clinical entity it has been known for many years. Its aetiology is, however, still obscure, and its treatment is unfortunately one of the failures of ophthalmology.

It has been thought that it might be a deficiency disease, and recent attempts to cure the condition by administration of vitamin $\mathrm{D}$ and calcium have been made. (Knapp, 1938.) Cantor (192 $)$ observed that there was an alteration in the shape of the cornea with the production of myopia and astigmatism in patients suffering from chronic keratomalacia. As it is now an established fact that keratomalacia or xerophthalmia is due to avitaminosis $\mathrm{A}$, it is surprising that so little has been done to establish some connection between keratomalacia and keratoconus. Gudjonsson (1930) mentions that keratoconus was in his experiments a frequent sequel to xerophthalmia in rats on a vitamin A-free diet. In the detailed description which he gives, however, keratoconus is not described but illustrations are given of what is called buphthalmos. No other detailed description of either condition can be found in the literature.

In a recent experiment at the Rowett Institute, certain rats which had been kept since weaning on a vitamin A-free diet until clinical symptoms of avitaminosis A were noted, were subsequently given a large daily dose of the vitamin. After some days it was observed that several of the rats were suffering from acute keratoconus. One rat showed distinct keratoconus before vitamin A dosage was begun. It was then decided to conduct a fresh experiment with the object of producing keratoconus in the rat, in order that the condition might be more closely studied.

\section{Experimental Technique}

Fifteen male and 15 female rats, belonging to four litters, were used in the experiment. Two of the litters were of the hooded strain and two were albinos.

In order that the reserve store of vitamin $\mathrm{A}$ in the young rats might be as low as possible, the mothers were given the experimental vitamin A-free diet at periods varying from five to thirteen 
days after parturition. The young were weaned at 23 days and placed on this ration which consisted of :-

$\begin{array}{lcccccc}\text { Casein (fat- and vitamin-free) } & \ldots & \ldots & \ldots & 18 \\ \text { Wheat starch } & \ldots & \ldots & \ldots & \ldots & \ldots & 50 \\ \text { Dried yeast } & \ldots & \ldots & \ldots & \ldots & \ldots & 18 \cdot 3 \\ \text { McCollum's salt } & \text { mixture } & (\text { No. } & 185) & \ldots & \ldots & 5 \\ \text { Hardened cottonseed oil } & \ldots & \ldots & \ldots & 15 \\ \text { Lemon juice } & \ldots & \ldots & \ldots & \ldots & \ldots & 5\end{array}$

with a small amount of pot. iodide solution ( $\cdot 0064 \mathrm{~g}$. KI for 300 $\mathrm{g}$. casein) and sufficient water to make into a stiff paste.

Vitamin D was given in the form of radiostol $(0.02 \mathrm{ml}$. per rat twice weekly).

\section{Occurrence of Xerophthalmia and Keratoconus}

Of the 30 rats in the experiment all developed xerophthalmia in some degree, but there was considerable variation in the time of appearance of the symptoms, in the severity of the eye lesion itself, and also in the severity of the xerophthalmia relative to other lesions. In most cases, moreover, xerophthalmia appeared in one eye in advance of the other, and was more acute in one eye. In 2 rats the first sign of xerophthalmia (retraction of the eyeball) was seen 20 days after weaning; in other rats the earliest symptoms were noted 22 to 36 days after weaning. In the case of the 2 rats which showed symptoms after 20 days, vitamin A dosage was begun 12 days later. One of the two recovered in 8 days, no apparent abnormality remaining in the eyes, while both eyes of the other animal perforated within 3 days. In some rats the eye condition appeared to be the chief lesion present, while in others the animal died from some visceral lesion before the xerophthalmia was very acute. Nine rats died before vitamin A dosage was begun, or within 3 days thereafter, and in 3 rats the eyes perforated. These rats were thus useless for the purpose of the experiment. Of the remainder, 12 developed keratoconus, and 4 of these were killed when the keratoconus had reached a maximum size.

Xerophthalmia in the rat.-The appearance of xerophthalmia in rats is well known to those engaged in vitamin $\mathrm{A}$ research work, but as acute xerophthalmia in human beings in this country is practically an unknown disease, many ophthalmic surgeons in all probability have never seen the condition. A clinical description will therefore not be out of place. As the rat eye and the human eye differ in shape a brief description of the anterior segment of the rat's eye is necessary. The most noticeable feature 
is the comparatively large cornea. It fills the whole of the palpebral fissure, projecting well forward between the eyelids, no white or sclerotic being visible. Consequently when such an eye is inflamed no redness of the eyeball can be seen.

The first sign of xerophthalmia in the rat is a retraction of the eyeball or enophthalmos. This early symptom may pass unnoticed, unless one keeps in mind the fact that the eyes of a healthy rat are very prominent. The enophthalmos is followed in 2 or 3 days by a narrowing of the palpebral fissure, lacrimation, and redness of the borders of the eyelids with possibly some debris lying near the internal canthus. The redness of the eyelids is more noticeable in the albino than in the hooded rat. After this stage the eye lesion appears to take one of two forms. In some animals the cornea becomes dry and lustreless, the lashes of the lower eyelid turn inwards and rub on the cornea, and there appears to be loss of corneal sensation. No further change may then take place until the rat dies from some visceral lesion. In others a dark brown discharge gathers on the borders of the eyelids and adheres to the cornea especially on its lower half, the cornea becomes uniformly cloudy, pus accumulates, the cornea disintegrates and the eye is destroyed.

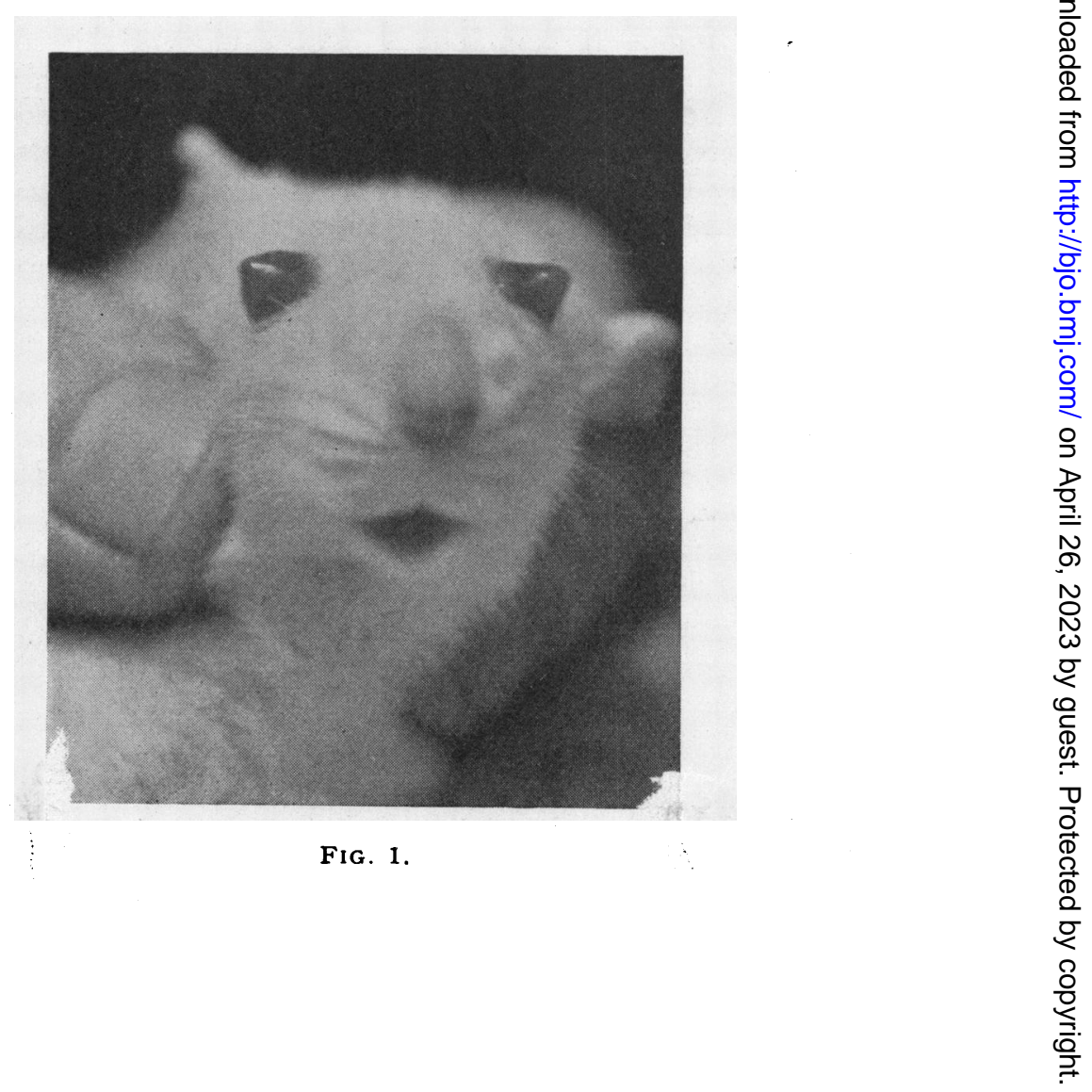


Production of keratoconus.-Keratoconus was produced only in rats that had acute xerophthalmia. The xerophthalmia was allowed to progress until the cornea showed a central haze, the animal being then given a concentrated dose of vitamin $\mathrm{A}$. If vitamin A was given too early, the eyes cleared up with remarkable rapidity, leaving apparently no abnormality, but if dosing was delayed too long the eye perforated and was useless for further experiment. In cases where keratoconus developed the sequence of the symptoms was as follows : by the second day following the administration of vitamin $\mathrm{A}$ the discharge had become much less, the eyes were partly open and the cornea showed a central protrusion. This protrusion increased and came to a point. It took on an average 10 days for the cone to reach a maximum size. Of the 12 rats which developed keratoconus, 3 showed the condition bilaterally. In one, the cones were so large and protruded to such an extent that the animal had difficulty in closing its eyelids over the tips of the cones. (Fig. 1.)

\section{Curability of Xerophthalmia and Keratoconus}

Xerophthalmia.- If dosing is begun early, acute xerophthalmia usually clears up very rapidly without leaving any apparent abnormality.

Keratoconus.- - If keratoconus has developed, the cornea may regain normal contour in a comparatively short time, but in all the cases we have observed, corneal nebulae remained, and the rats appeared either to have a less degree of hypermetropia or to be actually myopic. As several of the rats were killed when the cones reached a maximum size, we do not know whether or not the cones in some suffer no retrogression. Gudjonsson states, however, that sometimes rats cured of xerophthalmia have pronounced exophthalmos (sic) the rest of their lives.

Clinical examination of the surviving rats.-Seventy-six days after weaning the surviving 8 rats (which had had keratoconus) had atropine dropped into both eyes. All had corneal nebulae in one or both eyes. One still had a certain degree of keratoconus with vascularisation of the cornea. The pupils failed to dilate or dilated irregularly in 6 of the eyes that had suffered from keratoconus, anterior synechiae being present. The pupils of the remaining two dilated fully. All the eyes had suffered from acute xerophthalmia. It was possible to estimate the refraction in 10 eyes. One had 10 dioptres of hypermetropia, two had 8 dioptres, one 6 dioptres, three 2 dioptres, one 1 dioptre of myopia and two 2 dioptres of myopia. In all there was irregular astigmatism. No attempt was made to estimate the amount of regular astigmatism.

In normal rats it was found that the hooded breed averaged 8 
dioptres of hypermetropia while the albinos averaged 10 dioptres of hypermetropia. The refraction of all those examined did not vary more than one dioptre in rats of the same strain. The refractions were estimated by finding the highest plus lens in the ophthalmoscope that left the optic disc in clear focus. An attempt was made to estimate the refraction by retinoscopy but this was unsuccessful owing to the difficulty of controlling the rat, and also owing to the fact that any deviation from the optic axis gave a different value. This we suspected was due to the high convexity of the cornea and to the relatively large lens.

\section{Suggested Mechanism of the Production of Keratoconus in the Rat}

Fuchs divides ectasiae of the cornea into two main divisions :-

$\begin{array}{cr}\text { Ectasiae of inflammatory origin } & \text { Staphyloma } \\ \text { Ectasiae of non-inflammatory origin } & \text { Keratoconus } \\ \text { Keratoglobus }\end{array}$

Staphyloma is caused by perforation of the cornea with prolapse of the iris. As all rats were discarded when the cornea perforated this condition is not included.

Keratectasia is a protrusion of the cornea, subsequent to its weakening by some previous inflammatory process, such as interstitial keratitis or pannus. The cornea protrudes as a whole and not in the form of a cone.

Keratoconus.- The central portion of the cornea bulges forwards in the form of a cone without any sign of inflammatory symptoms.

Keratoglobus is a congenital defect and is not comparable to the conditions described in this paper.

The ectasiae produced in all the rats without exception were in the form of central cones. As has been already stated, all had acute xerophthalmia, but it is well known that acute xerophthalmia even in human beings is remarkable for its non-inflammatory nature. (Parsons, 1934.) The majority, but not all, had anterior synechiae and it is thought that in those so affected this might have been a factor in the production of the cones. With one exception (the rat in the original experiment) keratoconus was not observed until the 2 nd or 3rd day after vitamin A dosing had begun. The production of the keratoconus appeared to coincide with the opening of the eyelids, so it was thought that when the 
weakened cornea lost the support given by the tightly shut eyelids, it was unable to withstand the intra-ocular pressure, and bulged forwards. As it was not possible to measure the intraocular pressure clinically in the rat, it is not known whether or not the intra-ocular pressure was normal, but in the case of those with anterior synechiae it is suspected that it might have been raised. This in all probability was the case in the rat that developed keratoconus before vitamin A was given. Anterior synechiae had formed by some unknown means, and a temporary rise of intra-ocular pressure supervened which appeared to be too great for the weakened cornea to withstand.

Comparison with keratoconus in human beings.-In view of the occurrence of keratoconus in rats as a sequel to xerophthalmia, it seems probable that in countries where xerophthalmia among the human population is not uncommon, varying degrees of keratoconus should be found. This we understand from conversations with experts who saw the experimental rats, is true at least for Egypt. In Great Britain acute xerophthalmia is practically unknown. Chronic and low grade xerophthalmia due to sub-optimal intake of vitamin A may, however, be more prevalent than is realised. The cornea may be weakened by intermittent attacks and permanent stretching of the tissues may take place without obvious vascularisation or other pathological sign. Keratoconus in European countries is rare, myopia and myopic astigmatism are common; their production may be due to the same mechanism. We do not suggest that keratoconus is due in every case to avitaminosis A but we do know that from lack of vitamin A, eye lesions can be produced experimentally in rats in 100 per cent. of cases and keratoconus with comparative ease.

In the human child exactly similar eye lesions going on to perforation are produced by vitamin A deficiency. It does not appear to us unreasonable to think, therefore, that if a child is receiving, over a lengthy period, a diet deficient in vitamin $\mathrm{A}$, the cornea and sclerotic may become weakened and unable to withstand the increased pressure when the child is eventually given an adequate diet. The child may not develop keratoconus but probably will develop myopia or myopic astigmatism, if the pathological changes in man are comparable with those with rat.

\section{Summary}

Keratoconus has been produced experimentally as a sequel to acute xerophthalmia in rats on a vitamin A-free diet. In most cases the cornea regained its normal contour after a few weeks dosing with vitamin $A$, corneal nebulae and myopia remaining as permanent defects. 
The writers are indebted to Dr. J. T. Irving, Head of the Physiology Department, for his interest in this work.

\title{
BIBLIOGRAPHY
}

Cantor, S. J.-Med. Jl. of Australia, Vol. I, p. 822, 1927.

FUCHS, E.-Text-book of Ophthalmology, 4th Edition, p. 305, 1911.

Gudjonsson, S.-Acta Pathol. et Microbiol. Scandinavica, Supplementum IV. 1930.

- Acta Ophthal., Vol. VIII, 1930.

Knapp, A. H.-Jl. Amer. Med. Assoc., Vol. CX, p. 1993 (June), 1938.

Parsons, J. H.-Diseases of the Eye, 7th Edition, 1934.

\section{A COMPARISON OF LENS AND SKIASCOPE METHODS IN RETINOSCOPY WITH UNDILATED PUPILS}

\author{
BY
}

W. J. B. RIDDELL

GLASGOW

For over thirty years the routine refraction work in the Ophthalmic Institution in Glasgow has been carried out by means of a circular skiascope designed by $\mathrm{H}$. Wright Thomson. The instrument consists of a sheet aluminium wheel nine inches in diameter mounted on the end of a half inch aluminium tube which is fifty inches in length. Within the circumference of the disc lenses are fitted, the number of which is conditioned by their diameter. The instrument with which most of the subsequent observations were made has thirty-six half inch lenses of the following powers : plus $8 \cdot 0,7 \cdot 0,6 \cdot 0,5 \cdot 0,4 \cdot 0,3.5,3 \cdot 0,2 \cdot 75,25,2 \cdot 25,2 \cdot 0,1 \cdot 75$, $1.5,1.0,0.75,0.5$ and 0.25 , followed by the corresponding minus powers in the reverse order. When in use the tube is tucked well under the arm and the disc is rotated close to the patient's eye on a plane at right angles to the visual axis. With a little practice it is not difficult to keep the lenses close to the observed eye and also to maintain the working distance at a full metre. Failure to attend to these two points leads to obvious fallacies. It is my own practice to refract the right eye with my right eye and the left one with my left. This enables the patient to fix a distant target and thereby relax his accommodation. The side of the wheel facing the observer is painted white on the plus half and black on the minus; the strength of each lens is indicated in numerals visible to him. A folding type with a telescopic tube has also been made, but the essential features of the instrument have not been changed since its introduction. In the evolutionary series of such instruments the skiascope is a simplification of 